\title{
Mechanistic roles of autophagy in hematopoietic differentiation
}

Thomas Riffelmacher and Anna-Katharina Simon

Kennedy Institute of Rheumatology

University of Oxford

Roosevelt Drive, Headington, Oxford OX3 7FY UK

Corresponding author: katja.simon@imm.ox.ac.uk

Keywords: Autophagy, Differentiation, Hematopoiesis, Hematopoietic Stem Cell, Lineage Commitment

\section{Abbreviations}

AMPK

APL

Atg

B

CCCP

CLP

ER

ESC

FAO

GMP

HSC

ILC

LAP

LIR

mTOR

NAC

NK

NKP

OXPHOS

PC

PE

PI(3)K

RBC
5 ' adenosine monophosphate-activated protein kinase

Acute promyelocytic leukemia

Autophagy related gene

memory B cell

carbonyl cyanide 3-chlorophenylhydrazone

common lymphoid progenitor

endoplasmic reticulum

embryonic stem cell

fatty acid oxidation

granulocyte-macrophage progenitor

hematopoietic stem cell

innate lymphoid cell

LC3-associated phagocytosis

LC3 interacting region

mammalian target or Rapamycin

$\mathrm{N}$-acetyl-cysteine

natural killer cell

natural killer cell progenitor

oxidative phosphorylation

plasma cell

phosphatidylethanolamine

class III phosphatidylinositol 3-kinase

red blood cell 
ROS

RTK

$\mathbf{T}_{\text {MEM }}$

$\mathbf{T}_{\text {reg }}$

ULK1

VPS34 reactive oxygen species

receptor tyrosine kinase

Memory $\mathrm{T}$ cell

Regulatory $\mathrm{T}$ cell

unc-51-like kinase

vacuolar protein sorting 34

\begin{abstract}
Autophagy is increasingly recognized for its active role in development and differentiation. In particular, its role in the differentiation of hematopoietic cells has been extensively studied, likely because blood cells are accessible, easy to identify and purify and their progenitor tree is well defined. This review aims to discuss the mechanisms by which autophagy impacts on differentiation, using hematopoietic cell types as examples. Autophagy's roles include the remodeling during terminal differentiation, the maintenance of a long-lived cell type, and the regulation of the balance between self-renewal and quiescence in stem-like cells. We discuss and compare the mechanistic roles of autophagy, such as prevention of apoptosis, supply of energy metabolites and metabolic adaption, selective degradation of organelles and of regulatory factors.
\end{abstract}

\title{
1. Autophagy during hematopoietic differentiation: Introduction and molecular mechanism
}

Macroautophagy (hereafter referred to as autophagy) is a conserved cellular degradation pathway that recycles cellular content. The catabolic degradation of cellular constituents in turn frees up metabolites and the basic building blocks required in anabolic processes, such as cell growth, proliferation, remodeling, and differentiation. On a molecular level, a family of close to 40 autophagy related genes ('Atg' genes) is involved in this pathway [1]. These factors guide the selection and targeting of the cargo and control the growth of the autophagosome, a double membraned vesicle that then fuses with the lysosome to facilitate degradation of its contents and release of the recycled metabolites [1][2]. The signaling that leads to induction of autophagy is controlled by several signaling hubs, including mTOR and 
AMPK, and eventually converges on unc-51-like kinase (ULK1) complex that induces autophagosome nucleation by targeting the class III phosphatidylinositol 3-kinase (PI(3)K) complex, containing BECLIN 1 and VPS34 (vacuolar protein sorting 34). Further maturation of the autophagosome involves the ubiquitin-like protein lipidation system that conjugates phosphatidylethanolamine (PE) onto Atg8-family member MAP1LC3B (also referred to as LC3-I). The lipidated LC3 (referred to as LC3-II) is targeted to autophagosome membranes to aid their elongation, and is widely used to quantify autophagy. In mammals, several Atg8 homologs have been identified, some of which are involved in recruitment of selective autophagy receptors via their LC3-interacting motifs (LIR-domains) [3][4][5]. Although the Atg8 family may allow the intersection of selective and basal autophagy, the details of dynamic inter-regulation between the individual autophagy pathways remain incompletely understood. It is important to note that much of the molecular autophagy machinery is pleiotropic and the complex signaling mechanisms are highly interconnected with other cellular signaling such as ubiquitinylation, cell death, phagocytosis, secretion, and cell cycle. Details and open questions in these pathways have recently been reviewed [6] and will not be discussed here, although they will likely contribute to settling some of the current controversies in hematopoietic studies of autophagy.

While initially described as a starvation-induced, bulk degradative pathway with little specificity, it has become increasingly appreciated that a complex regulatory network governs the selection, activity and timing of autophagy degradation [7]. Supporting this view of specific cargo selection is i) the identification of a growing number of degradation cues (mostly mediated by the ubiquitin-code) [8] [9] ii) the family of selective autophagy receptors that mediate target specificity [7][10], and iii) the identification of other lysosome directed, highly selective autophagic pathways such as microautophagy, chaperone mediated autophagy and LC3-associated phagocytosis (LAP) [11][12][13]. The range of types of selective autophagy cargo is only recently being uncovered, with specific receptors identified for protein inclusions caused by aggregate-prone or misfolded proteins (aggrephagy), organelles such as peroxisomes (pexophagy), mitochondria (mitophagy), surplus endoplasmic reticulum (ER) (reticulophagy), parts of the nucleus (nucleophagy) and ribosomes (ribophagy) [7][14].

While the molecular network of the autophagy pathway itself (Atgs and the upstream signaling) has been thoroughly studied over the last two decades, much less is known about how autophagy produces cell biological change within a cell which leads to a specific cell fate. Regulation of autophagy has recently been shown to affect cell fates such as differentiation, self-renewal, survival or cell death in a number of cellular systems [15]. Whilst the phenotype of defective differentiation without autophagy is well studied in several 
hematopoietic cell types in vivo, most of these studies only speculate about the cargo that autophagy degrades to affect cell fate and differentiation in a context specific manner. The lack of knowledge on the link between autophagy activity and mechanisms which lead to differentiation may be improved by i) new tools to delete only one type of selective autophagy without affecting the LC3-conjugation system (e.g. specific deletion of mitophagy via Bnip3L) ii) tools to purify and observe dynamic change of autophagosomal content during differentiation iii) increased knowledge of transcription- and growth-factor independent cell biological and metabolic regulation of differentiation.

It has become increasingly appreciated that metabolic and cell biological changes may work side by side with transcriptional regulation to guide differentiation [16] [17] [18] and autophagy is a prominent candidate to execute these. Some of the selective mechanisms by which autophagy impacts differentiation fate are outlined below (see Figure 1).

i) Stress/Survival: A passive/permissive model of autophagy-mediated survival could select cells that are fit to differentiate while others may undergo apoptosis. Selective survival could be mediated by suppression of reactive oxygen species (ROS) and oxidative stress (mitophagy) or limiting ER-stress induced apoptosis (reticulophagy). By mitigating such stress, autophagy is known to prevent DNA damage and caspase activation, but can also directly crosstalk with the DNAdamage repair machinery [19] to facilitate survival. This pro survival role for autophagy is relevant to hematopoietic stem cell maintenance and will be further discussed in that section.

Another possibility is the prevention of caspase activation, and reciprocally caspases can cleave the autophagy protein $\operatorname{Atg} 5$ to disrupt autophagy. The interplay of caspases and autophagy during apoptosis is relevant to monocyte to macrophage differentiation [20] and we will further describe the evidence for this in the relevant section.

ii) Organelle Homeostasis: Selective autophagy of organelles can quickly remodel intracellular composition and adapt cytoplasmic content to reflect a new state of differentiation. The cellular content of organelles could determine cell fate rather than be a consequence, and some evidence exists for this in cardiomyocyte differentiation [21][22]. Since erythroblasts degrade their organelles during RBC differentiation, we will discuss autophagy and organelle homeostasis in the section on erythropoiesis.

iii) Energy Metabolism: ATP is the primary currency of cellular energy, and the interplay of glycolytic and mitochondrial metabolism determines its availability. Cellular remodeling during differentiation is an energy-consuming process, and 
autophagy may help to preserve ATP levels by recycling precious metabolites that otherwise need energy-expensive biosynthesis. By breaking down storage forms of energy such as lipids and glycogen, autophagy may further provide the ATP necessary for differentiation. While little is known about how autophagy can affect the metabolic balance within cells, the link between metabolism and differentiation is increasingly being understood [23]. T cell differentiation and fate is uniquely tied to metabolism and we will therefore use the respective section to discuss potential roles of autophagy in this context.

iv) Proteostasis: The proteome within a cell during differentiation is shaped by the sum of protein expression and degradation. By selectively removing specific regulatory factors via microautophagy or chaperone-mediated autophagy, cells can rapidly alter signaling outcome and differentiation. While evidence for this within the hematopoietic system is still lacking, plasma B cells uniquely rely on limiting aggregation of damaged proteins, and we discuss the implication of autophagy on protein homeostasis in this section.

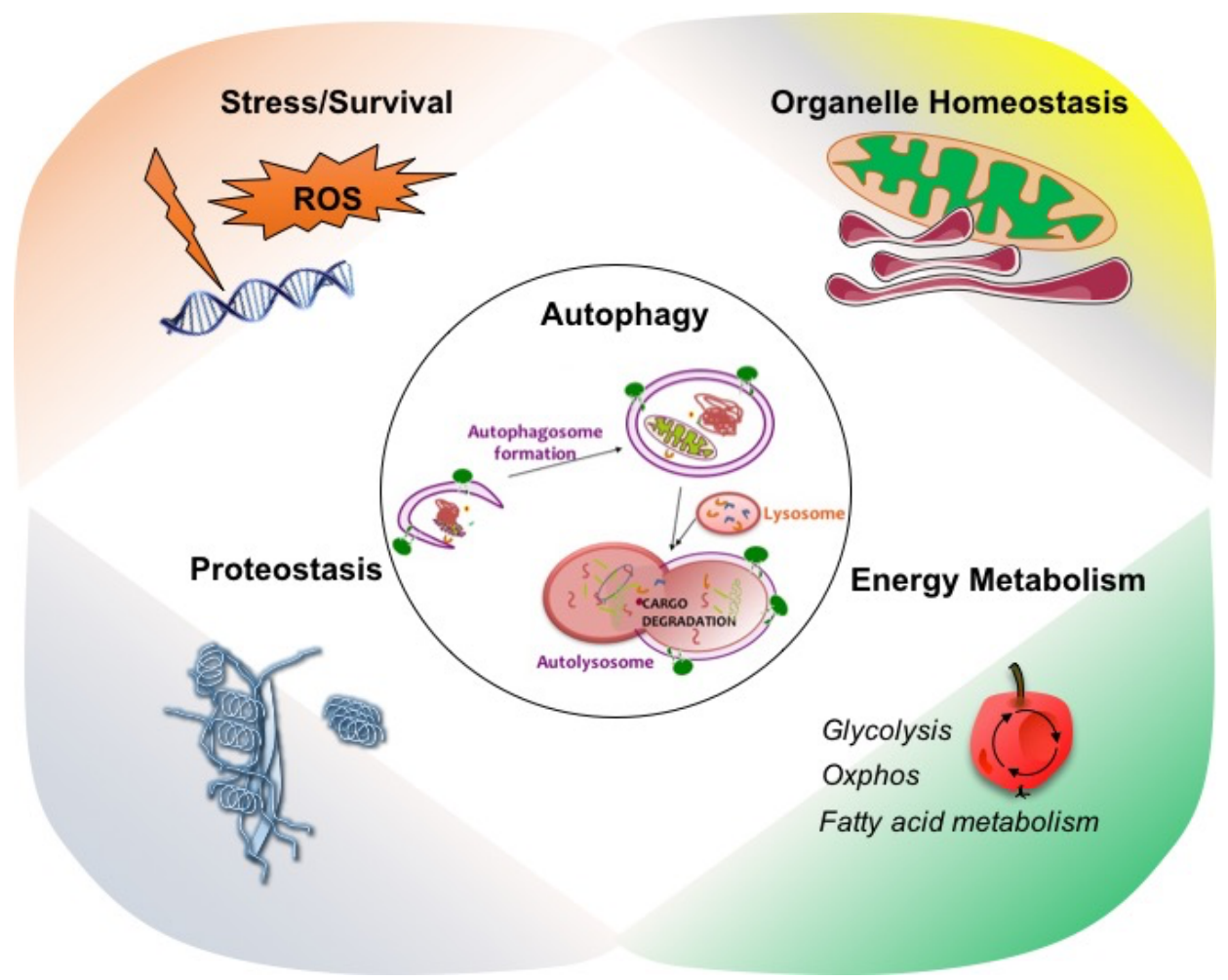

Figure 1 Effector roles or autophagy during differentiation

Autophagy can affect the differentiation of hematopoietic cells by mechanisms summarized here in four categories. By preventing ROS, ER-Stress, caspase activation and DNA damage, it may maintain survival of cells fit to differentiate (discussed in monocytemacrophage section). Homeostasis or organelles, particularly mitochondria, is important as cellular content undergoes rapid remodeling during differentiation (discussed in erythropoiesis section). Energy metabolic adaption is linked to autophagy by providing nutrients and ATP necessary for differentiation (discussed in T-cell section). Finally, protein homeostasis is maintained by regulated degradation of damaged and misfolded proteins via the proteasome and autophagy pathways (discussed in B-cell section). 


\section{Cellular case studies: autophagy affects the differentiation of hematopoietic cells}

a. Hematopoietic stem cells: Does autophagy regulate the balance of selfrenewal versus differentiation?

Hematopoiesis is defined as the stepwise differentiation of hematopoietic stem cells (HSCs) into progenitor cells with increasingly restricted potential, which eventually terminally differentiate to form all blood and immune cells. HSCs strike a fine balance between quiescence, self-renewal, and differentiation. Their position at the apex of the hematopoietic tree argues for the importance of cytoprotective pathways as part of their defense against accumulation of damage and dysfunction. Although there are only a few key studies that address the role of autophagy in HSCs [24] [25] [26], the critical importance of autophagy in this stem cell population can already be inferred indirectly from evidence of related pathways. In an unbiased approach, Cheung et al. compared the quiescent stem cell gene expression signature across multiple stem cell types and identified several genes in the autophagy pathway including Ulk2, Pink1, Atg8 homologs Gabarapl1, Mapllc3a and Foxo3 to be among the top 50 genes of the 'stemness' gene signature [27]. One of these, FOXO3A, a transcription factor maintaining quiescence of HSCs, has been shown to regulate autophagy in HSCs and protect them from metabolic stress during starvation or growth factor withdrawal. FOXO3 induces autophagy gene expression including Atg4b, Map1lc3b, and Bnip3 [24]. While this suggests elevated autophagy in stem cells at a genetic level, functional evidence confirms highest autophagy in HSCs and generally declining levels as progenitors increasingly commit to lineages [24] [28]. High autophagy levels in murine HSCs as measured by the autophagosome-specific dye CytoID and LC3-II colocalization with lysosomal LAMP-1 +/- flux inhibitor BafilomycinA1 in GFP-LC3 transgenic mice by imaging flow cytometry was also paralleled in human HSCs [28]. It is tempting to speculate that high activity of autophagy or mitophagy is uniquely crucial in highly quiescent cells as they are unable to dilute damaged mitochondria and ROS quickly to their daughter cells. That long-lived and quiescent cells require autophagy in particular is a hypothesis supported by paralleled data in long-lived memory $\mathrm{T}$ - and $\mathrm{B}$ - cells $\left(\mathrm{T}_{\mathrm{MEM}}\right.$ ) and $\left.\mathrm{B}_{\mathrm{MEM}}\right)$ described later. Indeed, robust mitophagic activity may be promoted by the hypoxic stem cell niche, which induces bnip3 and mitochondrial autophagy via HIF1a dependent mechanisms [29] and limits mitochondrial mass, oxygen consumption, and ROS production [30]. Similarly, inhibition of the mTOR pathway induces autophagy and also contributes to HSC quiescence by repressing mitochondrial activity while promoting glycolysis. During differentiation, a metabolic conversion from anaerobic glycolysis to mitochondrial oxidative phosphorylation takes place, 
and modifying this metabolic switch can be sufficient to alter the self-renewal versus differentiation decision of HSCs [31] [32] [33]. One example for this is the depletion of the mitochondrial phosphatase PTPMT1, which disrupts the transition from anaerobic glycolysis to mitochondrial metabolism and results in hematopoietic failure associated with accumulation of HSCs that cannot differentiate [34].

Mice deleted for autophagy in HSCs $\left(\operatorname{Atg} 5^{\mathrm{f} / \mathrm{f}}\right.$ and $\operatorname{Atg} 7^{\mathrm{f} / \mathrm{f}} \times$ Vav-Cre) display an initial expansion of the hematopoietic progenitor compartment at 6 weeks of age, which progresses to severe anemia and bone marrow failure after a complete loss of the stem cell compartment and death at around 10 weeks of age [28] [25]. Deletion via Fip200 ${ }^{\mathrm{f} / \mathrm{f}} \mathrm{x}$ Tie2-Cre is embryonically lethal and also characterized by a loss of HSCs. The difference in phenotype between these models may be due to the timing of deletion by the different promoters driving cre expression or additional gene specific effects on HSCs. The HSPC compartment in Atg7KO mice displays an accumulation of defective mitochondria, increased proliferation as measured by Ki67 staining, DNA damage, and, at 9 weeks, also increased cleaved caspase-3 [25]. Apoptosis could be caused by ROS or excessive DNA damage. However, whether the observed proliferation is a consequence of the cytopenias or cell intrinsic is still unclear. In support of the cell intrinsic hypothesis is a study showing autophagic signaling associated with ubiquitin-mediated degradation of Cyclin-D3 in HSPCs under nutrient stress [35]. However, the evidence presented for this is solely based on pharmacological inhibition of autophagy and therefore should be interpreted with caution. The link between autophagy and cell cycle is better supported by the finding that autophagy deficient acute myeloid leukemic cells which arise from the HSPC compartment, proliferate excessively [28]. Strategies to restore normal cell cycle or differentiation capability in autophagy deficient HSCs may therefore open new therapeutic avenues in myeloid malignancies.

\section{b. Erythropoiesis: A case for selective autophagy research}

The first observations that autophagy may be important in hematopoietic differentiation were made in red blood cell differentiation. During erythropoiesis, expulsion of the nucleus from erythroblasts leads to the formation of reticulocytes in the bone marrow. Subsequently most cellular organelles are removed during their terminal differentiation into RBCs in the periphery. Autophagy induction as observed by EM and fluorescence imaging occurs in the polychromatic erythroblast stage and goes along with high expression of several autophagy genes [36][37]. The targeted deletion of autophagy genes, including Ulk1 [38], Atg7 [37], Bnip3L [39][40] and Fip200 [26] causes defective erythroid differentiation and anemia. While 
some studies find retention of mitochondria and other organelles such as ribosomes without autophagy [38], normal ribosome-removal after deletion of the mitophagy-specific gene Bnip3L still leads to anemia and mitochondrial accumulation. Furthermore, mitochondrial clearance is diminished but not abolished in the absence of Atg5/7 [40][41], and the mitochondrial uncoupler CCCP is able to partially re-establish the removal of mitochondria in Ulk1- or Bnip3L-deficient erythroblasts. Together, this suggests the presence of alternative pathways that remove mitochondria during RBC differentiation [38][39]. One such pathway is non-canonical alternative autophagy, a mechanism that allows autophagosome-mediated degradation even in the absence of Atg 5 or Atg7 under certain conditions [42]. The relevance and mechanisms of the different degradative pathways for cellular organelles have mostly been described in basic model organisms. Certainly, the unique process of complete cellular organelle removal during erythropoiesis makes it an invaluable system to understand the regulated degradation of organelles. To date, only mitophagy can be disrupted genetically without affecting other autophagic pathways and the LC3-conjugation machinery. Identifying and characterizing the receptors and machinery for other selective organelle degradation systems may generate more such genetic tools where selective forms of autophagy can be deleted without affecting macroautophagy. However, redundancy of the receptor system in their specificity makes it challenging to target selected degradative pathways [7]. It therefore remains a major challenge in the field to overcome the limitations of blocking general autophagic degradation via deletion of 'core Atg' genes such as Atg5/7 and upstream regulators such as Fip200/Beclin 1. As will be evident from the following example cases, the loss of core Atg-KOs and regulator KOs is often severe and eventually causes apoptosis. As the field of selective autophagy research advances, the model of 'random' cytoplasmic macro-autophagy may eventually be entirely replaced by a 'selective targeting model' of each and every substrate into autophagosomes in a highly dynamic, regulated manner. In this model, deletion of the same core Atg gene may lead to different cellular outcomes, as the 'autophagic substratome' - the sum of the compounds targeted by autophagy at a given time point - may be entirely different depending on cell type or differentiation stage. This may be relevant to fine-tune the differentiation and function of cells.

\section{c. T Cell development: Autophagy and Energy Metabolism}

In contrast to most hematopoietic cells, $\mathrm{T}$ cells develop in a unique organ responsible for their development, the thymus. After egress from the bone marrow, the earliest thymic progenitors are double negative cells, expressing neither CD4 nor CD8 co-receptors, followed by a CD4 ${ }^{+}$ $\mathrm{CD} 8^{+}$double positive stage, and eventually becoming single positive, $\mathrm{CD} 4^{+}$or $\mathrm{CD} 8^{+} \mathrm{T}$ cells that will leave the thymus to circulate the periphery. 
During thymocyte development, autophagy is active specifically at the double negative stage. Deletion of Atg5 or Atg7 in double negative thymocytes by Lck-cre leads to a decrease of total thymocytes, and also induces significant apoptosis in peripheral $\mathrm{T}$ cells. Transplantation studies of Beclin $1^{-/}$ESCs into $\mathrm{Rag}^{-/-}$mice, revealed a block at the double negative stage, while mature $\mathrm{T}$ cells were not intrinsically affected [43]. While autophagy may be required at an early stage in differentiation and within the thymic microenvironment, several later studies also showed a survival defect of the peripheral $\mathrm{T}$ cell compartment without autophagy, which may be a consequence of accumulating waste over time [44].

While naïve $\mathrm{CD}^{+} \mathrm{T}$ cells seem capable to become effector cells without autophagy, the maintenance of long-lived memory $\mathrm{CD}^{+} \mathrm{T}$ Cells $\left(\mathrm{T}_{\mathrm{MEM}}\right)$ critically depends on it. Memory $\mathrm{T}$ cells are formed during the contraction phase of an initial immune response and remain as a small proportion of long lived, resting cells, that rapidly respond to future encounters with the same pathogen. As most quiescent cells, but unlike stem cells, $\mathrm{T}_{\text {MEM }}$ generate most of their energy via mitochondrial oxidative phosphorylation (OXPHOS) fueled by fatty acid oxidation (FAO) and thus undergo a metabolic switch during their formation from the highly glycolytic, proliferative effector $\mathrm{T}$ cell pool. This switch from anabolic to catabolic metabolism is accompanied by induced autophagic signaling as the effector $\mathrm{CD} 8^{+}$cells stop dividing just before the contraction phase [45]. In line with a role of autophagy during memory $\mathrm{T}$ cell formation is the finding that both AMPK signaling and mTOR inhibition promote $\mathrm{T}_{\mathrm{MEM}}$ formation, and are key in the activation of autophagy[46]. Indeed, when autophagy is conditionally disrupted in T cells in CD4-Cre $\times \operatorname{Atg} 7^{\mathrm{fl/}}$ or GnzB-Cre $\times \operatorname{Atg} 7^{\mathrm{fl/}}$ mouse models, the virus-specific $\mathrm{CD} 8^{+}$memory response was severely diminished and failed to establish protection from secondary infection [47][45]. Mechanistically, autophagy may be important to prevent apoptosis by sustaining the mitochondrial metabolism associated with memory formation. $\operatorname{Atg} 7^{-/-} \mathrm{T}_{\mathrm{MEM}}$ display mitochondrial ROS production, accumulation of depolarized mitochondria and increased glycolytic metabolism and apoptosis [47][48], but the functional relevance of mitochondrial and metabolic regulation by autophagy remains elusive.

Similar to $\mathrm{T}_{\mathrm{MEM}}$, regulatory $\mathrm{T}$ cells $\left(\mathrm{T}_{\mathrm{reg}}\right)$ are antigen-experienced cells that maintain a state of readiness over an extended period of time that allows them to respond quickly if and when they are needed. While in this homeostatic, non-proliferative state, $\mathrm{T}_{\text {reg }}$ cells switch to FAOdriven OXPHOS as main fuel source and have elevated levels of autophagy [49][50][51]. Two recent studies have shown that autophagy is indeed an essential player in $T_{\text {reg }}$ cell maintenance and function by supporting their metabolic adaption and prevention of excessive glycolysis [50][52]. While the authors note a decrease in the terminal differentiation marker KLRG-1 in $\mathrm{T}_{\mathrm{reg}}$ cells from Atg1611 ${ }^{\mathrm{f} / \mathrm{f}} \mathrm{x}$ foxp3-Cre mice, they conclude that autophagy deficiency mainly affects $T_{\text {reg }}$ cell maintenance and survival in the context of metabolic 
adaptation to the intestinal microenvironment. Lipid uptake and FAO gene expression is increased in colonic $\mathrm{T}_{\text {reg }}$ cells compared to those in the spleen or lymph nodes, while Atg1611 ${ }^{1-} \mathrm{T}_{\text {reg }}$ cells are unable to induce key FAO/FAS pathway genes.

In fact, it has been shown that limiting glycolytic activity with rapamycin is sufficient to promote expansion of $\mathrm{T}_{\text {reg }}$ cells in vitro and in vivo [53][54][55], although complete ablation of mTOR signaling in raptor deficient $T_{\text {reg }}$ leads to loss of functionality [56]. It is tempting to speculate that autophagy regulates $\mathrm{T}_{\text {reg }}$ homeostasis by controlling the supply of relevant metabolites or adapting their metabolic programming required to support $\mathrm{T}_{\text {reg }}$ fate and stability. Supporting this view, defective autophagy rewires the metabolism towards aerobic glycolysis, a fuel choice that may favor the generation of other $\mathrm{T}$ cell subsets, such as $\mathrm{T}$ helper 2 (Th2) cells [50].

\section{d. Autophagy in B cells: maintaining protein homeostasis and limiting reactive oxygen species}

B cells differentiate from HSCs in a stepwise manner. During early embryonic development, HSCs migrate to the fetal liver, where they differentiate into B cells during embryonic life. In adults, continuous B cell development occurs in the bone marrow throughout life. In the bone marrow progenitors, rearrangement and expression of the immunoglobulin gene takes place as they undergo stepwise differentiation through a number of stages, including pro-B, pre-B cells and immature B cells (Hardy fractions A-F). Immature B cells finally migrate to secondary lymphoid tissues, where they fully mature. B cells are classified into two subsets, B-1 and B-2, based on expression of the surface markers B220 and CD5. Whether B-1 cells are derived from distinct progenitors is still under investigation [57]. Autophagy activity, as measured by autophagosome abundance and Beclin 1 expression, is highest in pro-B cells and declines in pre-B cells and subsequent stages [58][59]. As in $\mathrm{T}$ cells, the kinetics of autophagy has functional relevance: Beclin 1 deficient Rag $^{-/-}$embryonic stem cell (ESC) chimeras have greatly reduced numbers of early B cells, while mature, peripheral populations are largely unaffected [43]. Similar results in Atg5 deficient $\mathrm{Rag}^{-/-}$chimeras suggest that the block in pro- to pre-B cell development is not gene specific but caused by autophagy-pathway deficiency resulting in increased cell death of these progenitor stages [60]. Importantly, in both these chimeric models HSCs lack autophagy, and the earliest stem and progenitor cells have been shown to critically require autophagy for their own maintenance and differentiation, potentially exacerbating the observed B cell phenotype [25]. Indeed, in a recent study using Mb1-cre-, CD19-cre or CD21-cre- mediated excision of Atg5 at different stages after the pro-B cell stage suggests that autophagy is dispensable for development after the pro-B cell stage [61]. It is intriguing to speculate that deletion of Atg-genes at an early 
stem/progenitor stage may have led to cell extrinsic homeostatic feedback, or allowed enough time for metabolic/signaling changes within the cell to develop. This could result in the failure to pass a survival checkpoint downstream at the pro- to pre-B cell stage. In contrast to the discrepancies of findings in B2 cell development, the requirement for autophagy to maintain a functional pool of B1 cells is uniformly reported in Atg5 embryonic stem cell $\left(\right.$ ESC) $->\operatorname{Rag}^{-/-}$chimeras, CD19-cre x $\operatorname{Atg} 5^{\mathrm{f} / \mathrm{f}}, \mathrm{CD} 19-\operatorname{cre} \times \operatorname{Atg} 7^{f / \mathrm{f}}$ and Mb1-cre $\times \operatorname{Atg} 5^{\mathrm{f} / \mathrm{f}}$. Autophagy may be necessary early during development in a progenitor that gives rise to B1 cells. It is an interesting open question why autophagy is specifically required for B1-a cell generation/maintenance compared to B-1b and B-2 cells, and how this may be linked to their unique fetal origin, their stem cell like self-renewing characteristics or distinct metabolic state [57].

After their encounter with antigen, B cells differentiate into plasma cells (PCs), the terminal effector cells that produce large amounts of antibody. During this process, a significant expansion of the ER, and activation of the unfolded protein and antioxidant responses are employed to cope with the stress associated with antibody production.

Autophagy is known to control ER homeostasis via reticulophagy and is important in many cell types to limit ROS and unfolded protein aggregation. Therefore, it is not surprising that PCs have high levels of autophagy compared to $\mathrm{CD} 19^{+} \mathrm{B}$ cells, as measured by lysotropic dyes, expression of autophagy genes and LC3-punctae quantification in GFP-LC3 ${ }^{+}$mice [62]. Deletion of autophagy in $\operatorname{Atg} 5^{\mathrm{f} / \mathrm{f}} \times \mathrm{CD} 19-\mathrm{Cre}$ mice leads to expanded ER and enhanced expression of the ER stress response genes $X b p-1$ and Bip, which in turn results in increased levels of the crucial PC transcriptional regulator blimp-1 and augmented antibody production. Autophagy therefore exerts its negative control of plasma cell ontogeny and immunoglobulin production via the unfolded protein response and ER stress [62].

Analogous to T cells, B cell memory differentiation is associated with elevated autophagy levels based on gene expression and LC3-II quantification, and deletion of Atg7 and Atg5 substantially diminishes the secondary antibody response [63]. Autophagy-deficient memory B cells generate increased quantities of mitochondrial ROS and lose mitochondrial membrane potential. Subsequent cell death cannot be rescued by apoptosis inhibitors, but can be prevented with Necro-X2, a necrosis inhibitor targeting ROS, as well as with the antioxidants $\mathrm{N}$-acetyl-cysteine (NAC) and Tempol. More specifically, Chen et al. show that the peroxidation of lipids eventually causes cell death, and this can be reversed by a specific antioxidant, a-Toc, or the deletion of the lipoxygenase Alox5 [63]. These examples show how B cell subsets rely on autophagy as a quality control pathway to prevent lipid-peroxidation, protein aggregation and excessive unfolded protein response. 
e. Monocyte-Macrophage differentiation and granulopoiesis: Overcome death with autophagy?

Monocytes are generated in the bone marrow via four intermediate maturational stages from monoblast precursors, which are ultimately derived from HSCs [64]. After entering the circulation, monocytes move into diverse tissues to terminally differentiate into various types of macrophages and dendritic cells. In the absence of a stimulus, monocytes undergo apoptosis in a caspase-dependent manner. If the cytokines GM-CSF or CSF-1 however trigger differentiation, apoptosis is prevented and differentiation into macrophages occurs. Several studies found that in both mouse and human, autophagy is activated during this differentiation step as observed via LC3-II formation on western blot and microscopy, and occurrence of double-membraned structures in electron micrographs [65][66]. This induction of autophagy is necessary to prevent caspase-3 induced apoptosis, as autophagy-inhibitors 3MA and Chloroquine as well as Beclin 1 knockdown cause caspase activation even in the presence of the survival and differentiation inducing cytokine GM-CSF. Mechanistically, JNK kinase phosphorylates the antiapoptotic protein BCL-2, which dissociates from BECLIN1, leading to activation of autophagy and survival [66]. The role of autophagy in mediating or facilitating the differentiation however remains elusive. It is likely that it plays additional roles to promoting survival, as a significant fraction of cells survived the partial Beclin 1 knockdown, but retained immature features during GM-CSF treatment [66]. A problem in this study is the use of non-specific inhibitors and partial knockdown to model autophagy-deficiency, but another study has confirmed the role of autophagy in monocytedifferentiation using Atg7-deficient mice [65]. A separate study however found autophagy important in the activation of macrophages and to prevent a pro-inflammatory, senescent phenotype [67]. Finally, LC3-associated phagocytosis (LAP) is an antibacterial mechanism in monocytes and macrophages that shares some of the molecular machinery with autophagy [11] [6]. Monocyte to macrophage differentiation will be an interesting model to understand the interplay of autophagy and apoptosis and how autophagy regulation can affect the differentiation into macrophages on a molecular level.

Granulopoiesis defines the stepwise differentiation of hematopoietic progenitor cells in the bone marrow to become eosinophils, basophils or neutrophils. Neutrophils are the most abundant leukocyte, whereas basophils and eosinophils are rare cell types and less well studied. Derived from the granulocyte-macrophage progenitor (GMP), myeloblasts are the first committed neutrophil precursor, which undergoes five defined stages of maturation before terminal differentiation. While no evidence connects autophagy with eosinophil and basophil differentiation, there is indirect evidence that autophagy may either augment 
[68][69][70] or hinder [71] neutrophil differentiation. As these studies address differentiation mostly in the context of acute promyelocytic leukemia (APL) cells or in oncogenetransformed lines, it currently remains unknown how autophagy may affect neutrophil differentiation.

\section{f. Innate lymphocytes and NK cell memory: Another kind of memory dependent of autophagy?}

The family of innate lymphocytes consist of mature NK (mNK) cells, group 1 innate lymphoid cells (ILC1s), group 2 ILCs (ILC2s), and group 3 ILCs (ILC3s). Innate lymphoid cells are derived from the common lymphoid progenitor (CLP), and ultimately from HSCs, within the bone marrow. They lack somatic receptor rearrangement and do not express a $\mathrm{T}$ - or B- cell receptor. Most abundant following viral infection are NK cells, which bridge the innate and adaptive immune system [72]. They do not require activation to elicit effector function (hence "natural" killers). Following viral infections, NK cells proliferate and perform cytokine secretion and granule mediated cytotoxicity, before they contract after viral control. During their differentiation, CLP-derived natural killer progenitors (NKPs) differentiate into immature NK cells (iNKs) and further into mature NKs (mKNs). As observed during differentiation of $\mathrm{B}$ - and $\mathrm{T}$ cell progenitors, highly stage specific kinetic regulation of autophagy occurs in committed NK progenitors: while NKPs and mNKs have comparably low levels of autophagy, the intermediate iNK stage has high LC3-II turnover as measured by flow cytometry, immunofluorescence and immuno-EM in GFP-LC3-transgenic mice [73]. Consequently, NK-progenitor specific deletion of $\operatorname{Atg} 5$ in $\operatorname{Atg} 5^{\mathrm{f} / \mathrm{f}}$ x NKp46-Cre mice leads to a drastic decrease in iNKs and mNKs in BM and spleen. Silencing of Atg3 and $\operatorname{Atg} 7$ confirmed that this is indeed not gene specific but a general autophagic dependency. Although the authors note increased damaged mitochondria and ROS leading to elevated apoptosis, it remains unknown whether this is causative for the observed differentiation defect. In fact, ablation of mitophagy in Bnip3- and Bnip $3 L$-deficient mice did not result in NK-developmental or -functional defects, although mitochondrial damage and dysfunction are common to both models [74]. This suggests that core Atg-gene driven autophagy performs functions other than mitophagic organelle homeostasis to govern NK cell development. Since the exact order and definition of maturational stages during NK cell development has only recently been discovered, it is likely that further research into the cell biology of these subsets will lead to better understanding of the cell-intrinsic signaling necessary for NK cell fate [75]. Notch signaling, several receptor-tyrosine-kinases (RTKs) and regulation via miRNA-181 have all been described to be important during NK cell differentiation [76][77][78]. Over-abundance of miRNAs in ERI1-exonuclease deficient mice 
blocks NK development, and knockdown of the notch-inhibiting nemo-like kinase (NLK) promotes NK differentiation [79][77]. Maybe the finely tuned, stage specific autophagy activation in iNK cells mediates the removal of a differentiation-inhibiting factor such as NLK or certain miRNA species via selective forms of autophagy.

The existence of NK cell memory is a relatively recent concept that followed from the observation that during the contraction of the primary response, a small population of longlived, self-renewing cells remains that acquires features of immunological memory against secondary infection. Recent evidence suggests that BNIP3 and BNIP3L-dependent mitophagy may be important in these cells and prevents accumulation of mitochondrial ROS, as has previously been described for B- and T-cell memory. It is tempting to speculate that selfrenewing cells are generally dependent on this process to maintain cytoplasmic homeostasis. The primary function of mitophagy in this context could either be to prevent mtROS and loss of membrane potential, prevent leakage of mitochondrial signaling factors, or to sustain the function of mitochondria for ATP generation and metabolic homeostasis.

Finally, natural killer T (NKT) cells share features of both $\mathrm{T}$ cells and NK cells, and their differentiation has similarly been shown to require autophagy [80].

\section{Conclusions and Outlook}

In this review, we have discussed how autophagy is regulated during hematopoietic lineage commitment and how it may act to affect differentiation. A visual summary of the described findings from this fast-moving research field can be found in figure 2. While many of the proposed mechanisms remain hypothetical, circumstantial evidence from a number of the described systems suggests that there may be diverse and fascinating pathways intimately linked to autophagy to control differentiation. This ranges from control of metabolic adaption in $\mathrm{T}$ cell lineage commitment to organelle homeostasis in RBC and ILC differentiation or prevention of apoptosis during macrophage generation. Most of the discussed research has been thoroughly conducted in vivo with tissue specific deletion of several autophagy genes and well-characterized phenotypes. It has often proven difficult however to fully unravel the specific cargos of autophagy and how this facilitates such effects (summarized in table 1). We anticipate that new genetic models to delete selective forms of autophagy and new technologies to study the dynamic content of autophagosomes will enrich our understanding of the cell biology involved in hematopoietic differentiation. 


\section{Acknowledgements}

This work was supported by grants from the Medical Research Council (PhD prize studentship for Thomas Riffelmacher) and the Wellcome Trust (Investigator award to Anna Katharina Simon).

\section{Author contributions}

Thomas Riffelmacher conceived and wrote the manuscript and prepared the figures with contributions and under the guidance of Anna Katharina Simon.

\section{Citations}

1 Mizushima N, Yoshimori T \& Ohsumi Y (2011) The role of Atg proteins in autophagosome formation. Annu. Rev. Cell Dev. Biol. 27, 107-132.

2 Yang Z \& Klionsky DJ (2010) Eaten alive: a history of macroautophagy. Nat. Cell Biol. 12, 814-822.

3 Slobodkin MR \& Elazar Z (2013) The Atg8 family: multifunctional ubiquitinlike key regulators of autophagy. Essays Biochem. 55, 51-64.

4 Birgisdottir ÅB, Lamark T \& Johansen T (2013) The LIR motif - crucial for selective autophagy. J Cell Sci 126, 3237-3247.

5 Behrends C, Sowa ME, Gygi SP \& Harper JW $(2010)$ Network organization of the human autophagy system. Nature 466, 68-76.

6 Lindqvist LM, Simon AK \& Baehrecke EH (2015) Current questions and possible controversies in autophagy. Cell Death Discov. 1, 15036.

7 Stolz A, Ernst A \& Dikic I (2014) Cargo recognition and trafficking in selective autophagy. Nat. Cell Biol. 16, 495-501.

8 Kirkin V, McEwan DG, Novak I \& Dikic I (2009) A role for ubiquitin in selective autophagy. Mol. Cell 34, 259-269.

9 Shaid S, Brandts CH, Serve H \& Dikic I (2013) Ubiquitination and selective autophagy. Cell Death Differ. 20, 21-30.

10 Farré J-C \& Subramani S (2016) Mechanistic insights into selective autophagy pathways: lessons from yeast. Nat. Rev. Mol. Cell Biol.

11 Martinez J, Malireddi RKS, Lu Q, Cunha LD, Pelletier S, Gingras S, Orchard R, Guan J-L, Tan H, Peng J, Kanneganti T-D, Virgin HW \& Green DR (2015) Molecular characterization of LC3-associated phagocytosis reveals distinct roles for Rubicon, NOX2 and autophagy proteins. Nat. Cell Biol. 17, 893-906.

12 Li W, Li J \& Bao J (2011) Microautophagy: lesser-known self-eating. Cell. Mol. Life Sci. 69, 1125-1136.

13 Cuervo AM \& Wong E (2014) Chaperone-mediated autophagy: roles in disease and aging. Cell Res. 24, 92-104. 
14 Mancias JD \& Kimmelman AC (2016) Mechanisms of Selective Autophagy in Normal Physiology and Cancer. J. Mol. Biol. 428, 1659-1680.

15 Mizushima N \& Levine B (2010) Autophagy in mammalian development and differentiation. Nat. Cell Biol. 12, 823-830.

16 Warr MR \& Passegué E (2013) Metabolic Makeover for HSCs. Cell Stem Cell 12, 1-3.

17 Shyh-Chang N \& Daley GQ (2015) Metabolic Switches Linked to Pluripotency and Embryonic Stem Cell Differentiation. Cell Metab. 21, 349-350.

18 Suda T, Takubo K \& Semenza GL (2011) Metabolic regulation of hematopoietic stem cells in the hypoxic niche. Cell Stem Cell 9, 298-310.

19 Vessoni AT, Filippi-Chiela EC, Menck CF \& Lenz G (2013) Autophagy and genomic integrity. Cell Death Differ. 20, 1444-1454.

20 Jacquel A, Obba S, Solary E \& Auberger P (2012) Proper macrophagic differentiation requires both autophagy and caspase activation. Autophagy 8, 1141-1143.

21 Kasahara A, Cipolat S, Chen Y, Dorn GW \& Scorrano L (2013) Mitochondrial fusion directs cardiomyocyte differentiation via calcineurin and Notch signaling. Science 342, 734-737.

22 San Martin N, Cervera AM, Cordova C, Covarello D, McCreath KJ \& Galvez BG (2011) Mitochondria determine the differentiation potential of cardiac mesoangioblasts. Stem Cells Dayt. Ohio 29, 1064-1074.

23 Agathocleous M \& Harris WA (2013) Metabolism in physiological cell proliferation and differentiation. Trends Cell Biol. 23, 484-492.

24 Warr MR, Binnewies M, Flach J, Reynaud D, Garg T, Malhotra R, Debnath J \& Passegué E (2013) FOXO3A directs a protective autophagy program in haematopoietic stem cells. Nature 494, 323-327.

25 Mortensen M, Soilleux EJ, Djordjevic G, Tripp R, Lutteropp M, Sadighi-Akha E, Stranks AJ, Glanville J, Knight S, Jacobsen S-EW, Kranc KR \& Simon AK (2011) The autophagy protein Atg7 is essential for hematopoietic stem cell maintenance. J. Exp. Med. 208, 455-467.

26 Liu F, Lee JY, Wei H, Tanabe O, Engel JD, Morrison SJ \& Guan J-L (2010) FIP200 is required for the cell-autonomous maintenance of fetal hematopoietic stem cells. Blood 116, 4806-4814.

27 Cheung TH \& Rando TA (2013) Molecular regulation of stem cell quiescence. Nat. Rev. Mol. Cell Biol. 14, 329-340.

28 Watson A, Riffelmacher T, Stranks A, Williams 0, De Boer J, Cain K, MacFarlane M, McGouran J, Kessler B, Khandwala S, Chowdhury O, Puleston D, Phadwal K, Mortensen M, Ferguson D, Soilleux E, Woll P, Jacobsen S \& Simon A (2015) Autophagy limits proliferation and glycolytic metabolism in acute myeloid leukemia. Cell Death Discov. 1, 15008.

29 Zhang H, Bosch-Marce M, Shimoda LA, Tan YS, Baek JH, Wesley JB, Gonzalez FJ \& Semenza GL (2008) Mitochondrial Autophagy Is an HIF-1-dependent Adaptive Metabolic Response to Hypoxia. J. Biol. Chem. 283, 1089210903.

30 Jensen KS, Binderup T, Jensen KT, Therkelsen I, Borup R, Nilsson E, Multhaupt H, Bouchard C, Quistorff B, Kjaer A, Landberg G \& Staller P (2011) FoxO3A promotes metabolic adaptation to hypoxia by antagonizing Myc function: 
FoxO3A inhibits Myc to control hypoxic metabolism. EMBO J. 30, 45544570.

31 Gan B, Hu J, Jiang S, Liu Y, Sahin E, Zhuang L, Fletcher-Sananikone E, Colla S, Wang YA, Chin L \& DePinho RA (2010) Lkb1 regulates quiescence and metabolic homeostasis of haematopoietic stem cells. Nature 468, 701704.

32 Nakada D, Saunders TL \& Morrison SJ (2010) Lkb1 regulates cell cycle and energy metabolism in haematopoietic stem cells. Nature 468, 653-658.

33 Gurumurthy S, Xie SZ, Alagesan B, Kim J, Yusuf RZ, Saez B, Tzatsos A, Ozsolak F, Milos P, Ferrari F, Park PJ, Shirihai OS, Scadden DT \& Bardeesy N (2010) The Lkb1 metabolic sensor maintains haematopoietic stem cell survival. Nature 468, 659-663.

34 Yu W-M, Liu X, Shen J, Jovanovic O, Pohl EE, Gerson SL, Finkel T, Broxmeyer HE \& Qu C-K (2013) Metabolic regulation by the mitochondrial phosphatase PTPMT1 is required for hematopoietic stem cell differentiation. Cell Stem Cell 12, 62-74.

35 Cao Y, Zhang A, Cai J, Yuan N, Lin W, Liu S, Xu F, Song L, Li X, Fang Y, Wang Z, Wang Z, Wang J, Zhang H, Zhao W, Hu S, Zhang S \& Wang J (2015) Autophagy regulates the cell cycle of murine HSPCs in a nutrientdependent manner. Exp. Hematol. 43, 229-242.

36 Betin VMS, Singleton BK, Parsons SF, Anstee DJ \& Lane JD (2013) Autophagy facilitates organelle clearance during differentiation of human erythroblasts: evidence for a role for ATG4 paralogs during autophagosome maturation. Autophagy 9, 881-893.

37 Mortensen M \& Simon AK (2010) Nonredundant role of Atg7 in mitochondrial clearance during erythroid development. Autophagy 6, 423-425.

38 Kundu M, Lindsten T, Yang C-Y, Wu J, Zhao F, Zhang J, Selak MA, Ney PA \& Thompson CB (2008) Ulk1 plays a critical role in the autophagic clearance of mitochondria and ribosomes during reticulocyte maturation. Blood 112, 1493-1502.

39 Sandoval H, Thiagarajan P, Dasgupta SK, Schumacher A, Prchal JT, Chen M \& Wang J (2008) Essential role for Nix in autophagic maturation of erythroid cells. Nature 454, 232-235.

40 Matsui M, Yamamoto A, Kuma A, Ohsumi Y \& Mizushima N (2006) Organelle degradation during the lens and erythroid differentiation is independent of autophagy. Biochem. Biophys. Res. Commun. 339, 485-489.

41 Zhang J, Randall MS, Loyd MR, Dorsey FC, Kundu M, Cleveland JL \& Ney PA (2009) Mitochondrial clearance is regulated by Atg7-dependent and independent mechanisms during reticulocyte maturation. Blood 114, 157-164.

42 Nishida Y, Arakawa S, Fujitani K, Yamaguchi H, Mizuta T, Kanaseki T, Komatsu M, Otsu K, Tsujimoto Y \& Shimizu S (2009) Discovery of Atg5/Atg7independent alternative macroautophagy. Nature 461, 654-658.

43 Arsov I, Adebayo A, Kucerova-Levisohn M, Haye J, Mac-Neil M, Papavasiliou FN, Yue Z \& Ortiz BD (2011) A role for autophagic protein Beclin 1 early in lymphocyte development. J. Immunol. Baltim. Md 1950 186, 22012209.

44 Bronietzki AW, Schuster M \& Schmitz I (2015) Autophagy in T-cell development, activation and differentiation. Immunol. Cell Biol. 93, 25-34. 
45 Xu X, Araki K, Li S, Han J-H, Ye L, Tan WG, Konieczny BT, Bruinsma MW, Martinez J, Pearce EL, Green DR, Jones DP, Virgin HW \& Ahmed R (2014) Autophagy is essential for effector CD8+ T cell survival and memory formation. Nat. Immunol.

46 Araki K, Turner AP, Shaffer VO, Gangappa S, Keller SA, Bachmann MF, Larsen CP \& Ahmed R (2009) mTOR regulates memory CD8 T-cell differentiation. Nature 460, 108-112.

47 Puleston DJ, Zhang H, Powell TJ, Lipina E, Sims S, Panse I, Watson AS, Cerundolo V, Townsend AR, Klenerman P \& Simon AK (2014) Autophagy is a critical regulator of memory CD8+ T cell formation. eLife $3, \mathrm{e} 03706$.

48 Schlie K, Westerback A, DeVorkin L, Hughson LR, Brandon JM, MacPherson S, Gadawski I, Townsend KN, Poon VI, Elrick MA, Côté HCF, Abraham N, Wherry EJ, Mizushima N \& Lum JJ (2015) Survival of Effector CD8+ T Cells during Influenza Infection Is Dependent on Autophagy. J. Immunol. 194, 4277-4286.

49 Michalek RD, Gerriets VA, Jacobs SR, Macintyre AN, MacIver NJ, Mason EF, Sullivan SA, Nichols AG \& Rathmell JC (2011) Cutting Edge: Distinct Glycolytic and Lipid Oxidative Metabolic Programs Are Essential for Effector and Regulatory CD4+ T Cell Subsets. J. Immunol. Baltim. Md 1950 186, 3299-3303.

50 Kabat AM, Harrison OJ, Riffelmacher T, Moghaddam AE, Pearson CF, Laing A, Abeler-Dörner L, Forman SP, Grencis RK, Sattentau Q, Simon AK, Pott J \& Maloy KJ (2016) The autophagy gene Atg16l1 differentially regulates Treg and TH2 cells to control intestinal inflammation. eLife 5, e12444.

51 MacIver NJ, Michalek RD \& Rathmell JC (2013) Metabolic Regulation of T Lymphocytes. Annu. Rev. Immunol. 31, 259-283.

52 Wei J, Long L, Yang K, Guy C, Shrestha S, Chen Z, Wu C, Vogel P, Neale G, Green DR \& Chi H (2016) Autophagy enforces functional integrity of regulatory T cells by coupling environmental cues and metabolic homeostasis. Nat. Immunol. 17, 277-285.

53 Haxhinasto S, Mathis D \& Benoist C (2008) The AKT-mTOR axis regulates de novo differentiation of CD4+Foxp3+ cells. J. Exp. Med. 205, 565-574.

54 Kang J, Huddleston SJ, Fraser JM \& Khoruts A (2008) De novo induction of antigen-specific CD4+CD25+Foxp3+ regulatory T cells in vivo following systemic antigen administration accompanied by blockade of mTOR. J. Leukoc. Biol. 83, 1230-1239.

55 Battaglia M, Stabilini A \& Roncarolo M-G (2005) Rapamycin selectively expands CD4+CD25+FoxP3+ regulatory T cells. Blood 105, 4743-4748.

56 Zeng H, Yang K, Cloer C, Neale G, Vogel P \& Chi H (2013) mTORC1 couples immune signals and metabolic programming to establish Treg-cell function. Nature 499, 485-490.

57 Montecino-Rodriguez E \& Dorshkind K (2012) B-1 B Cell Development in the Fetus and Adult. Immunity 36, 13-21.

58 Arsov I, Li X, Matthews G, Coradin J, Hartmann B, Simon AK, Sealfon SC \& Yue $\mathrm{Z}$ (2008) BAC-mediated transgenic expression of fluorescent autophagic protein Beclin 1 reveals a role for Beclin 1 in lymphocyte development. Cell Death Differ. 15, 1385-1395.

59 Clarke AJ, Ellinghaus U, Cortini A, Stranks A, Simon AK, Botto M \& Vyse TJ (2014) Autophagy is activated in systemic lupus erythematosus and 
required for plasmablast development. Ann. Rheum. Dis., annrheumdis2013-204343.

60 Miller B, Zhao Z, Stephenson L, Cadwell K, Pua H, Lee H, Mizushima N, Iwasaki A, He Y-W, Swat W \& Virgin H (2008) The autophagy gene ATG5 plays an essential role in B lymphocyte development. Autophagy 4.

61 Arnold J, Murera D, Arbogast F, Fauny J-D, Muller S \& Gros F (2016) Autophagy is dispensable for B-cell development but essential for humoral autoimmune responses. Cell Death Differ. 23, 853-864.

62 Pengo N, Scolari M, Oliva L, Milan E, Mainoldi F, Raimondi A, Fagioli C, Merlini A, Mariani E, Pasqualetto E, Orfanelli U, Ponzoni M, Sitia R, Casola S \& Cenci $S$ (2013) Plasma cells require autophagy for sustainable immunoglobulin production. Nat. Immunol. 14, 298-305.

63 Chen M, Hong MJ, Sun H, Wang L, Shi X, Gilbert BE, Corry DB, Kheradmand F \& Wang J (2014) Essential role for autophagy in the maintenance of immunological memory against influenza infection. Nat. Med.

64 Goasguen JE, Bennett JM, Bain BJ, Vallespi T, Brunning R \& Mufti GJ (2009) Morphological evaluation of monocytes and their precursors. Haematologica 94, 994-997.

65 Jacquel A, Obba S, Boyer L, Dufies M, Robert G, Gounon P, Lemichez E, Luciano F, Solary E \& Auberger P (2012) Autophagy is required for CSF-1-induced macrophagic differentiation and acquisition of phagocytic functions. Blood 119, 4527-4531.

66 Zhang Y, Morgan MJ, Chen K, Choksi S \& Liu Z (2012) Induction of autophagy is essential for monocyte-macrophage differentiation. Blood 119, 28952905.

67 Stranks AJ, Hansen AL, Panse I, Mortensen M, Ferguson DJP, Puleston DJ, Shenderov K, Watson AS, Veldhoen M, Phadwal K, Cerundolo V \& Simon AK (2015) Autophagy Controls Acquisition of Aging Features in Macrophages. J. Innate Immun. 7, 375-391.

68 Xie N, Zhong L, Liu L, Fang Y, Qi X, Cao J, Yang B, He Q \& Ying M (2014) Autophagy contributes to dasatinib-induced myeloid differentiation of human acute myeloid leukemia cells. Biochem. Pharmacol. 89, 74-85.

69 Isakson P, Bjørås M, Bøe SO \& Simonsen A (2010) Autophagy contributes to therapy-induced degradation of the PML/RARA oncoprotein. Blood 116, 2324-2331.

70 Haimovici A, Brigger D, Torbett BE, Fey MF \& Tschan MP (2014) Induction of the autophagy-associated gene MAP1S via PU.1 supports APL differentiation. Leuk. Res. 38, 1041-1047.

71 Rožman S, Yousefi S, Oberson K, Kaufmann T, Benarafa C \& Simon HU (2014) The generation of neutrophils in the bone marrow is controlled by autophagy. Cell Death Differ.

72 Artis D \& Spits H (2015) The biology of innate lymphoid cells. Nature 517, 293-301.

73 Wang S, Xia P, Huang G, Zhu P, Liu J, Ye B, Du Y \& Fan Z (2016) Fox01mediated autophagy is required for NK cell development and innate immunity. Nat. Commun. 7, 11023.

74 O'Sullivan TE, Johnson LR, Kang HH \& Sun JC (2015) BNIP3- and BNIP3LMediated Mitophagy Promotes the Generation of Natural Killer Cell Memory. Immunity 43, 331-342. 
$75 \mathrm{Yu}$ J, Freud AG \& Caligiuri MA (2013) Location and cellular stages of natural killer cell development. Trends Immunol. 34, 573-582.

76 Beck RC, Padival M, Yeh D, Ralston J, Cooke KR \& Lowe JB (2009) The Notch Ligands Jagged2, Delta1, and Delta4 Induce Differentiation and Expansion of Functional Human NK Cells from CD34+ Cord Blood Hematopoietic Progenitor Cells. Biol. Blood Marrow Transplant. 15, 1026-1037.

77 Cichocki F, Felices M, McCullar V, Presnell SR, Al-Attar A, Lutz CT \& Miller JS (2011) Cutting edge: microRNA-181 promotes human NK cell development by regulating Notch signaling. J. Immunol. Baltim. Md 1950 187, 6171-6175.

78 Park I-K, Trotta R, Yu J \& Caligiuri MA (2013) Axl/Gas6 pathway positively regulates FLT3 activation in human natural killer cell development. Eur. J. Immunol. 43, 2750-2755.

79 Thomas MF, Abdul-Wajid S, Panduro M, Babiarz JE, Rajaram M, Woodruff P, Lanier LL, Heissmeyer V \& Ansel KM (2012) Eri1 regulates microRNA homeostasis and mouse lymphocyte development and antiviral function. Blood 120, 130-142.

80 Salio M, Puleston DJ, Mathan TSM, Shepherd D, Stranks AJ, Adamopoulou E, Veerapen N, Besra GS, Hollander GA, Simon AK \& Cerundolo V (2014) Essential role for autophagy during invariant NKT cell development. Proc. Natl. Acad. Sci. U. S. A. 111, E5678-5687. 


\begin{tabular}{|c|c|c|c|}
\hline Model & $\begin{array}{c}\text { Target } \\
\text { tissue/cell }\end{array}$ & Phenotype/Mechanism & Citation \\
\hline $\begin{array}{l}\operatorname{Atg} 5 / 7^{\mathrm{f} / \mathrm{f}} \text { Lck-Cre } \\
\begin{array}{c}\text { Beclin } 1 \text {-> } \text { Rag }^{-/-} \\
\text {chimera }\end{array}\end{array}$ & $\begin{array}{l}\text { Early T cell } \\
\text { development }\end{array}$ & $\begin{array}{l}\text { Block at double negative developmental } \\
\text { stage (controversial), mechanism unclear }\end{array}$ & $\begin{array}{l}{[43]} \\
{[44]} \\
{[45]}\end{array}$ \\
\hline $\begin{array}{l}\operatorname{Atg} 16 l 1^{\mathrm{f} / \mathrm{f}} \times \text { Foxp3-Cre } \\
\operatorname{Atg} 1611^{\mathrm{f} / \mathrm{f}} \times \text { CD4-Cre } \\
\operatorname{Atg} 7^{\mathrm{f} / \mathrm{f}} \times \text { Foxp3-Cre }\end{array}$ & $\begin{array}{l}\text { Regulatory T- } \\
\text { cells }\end{array}$ & $\begin{array}{l}\text { Intestinal inflammation, prevention of } \\
\text { excessive glycolysis, metabolic adaption }\end{array}$ & $\begin{array}{l}{[50]} \\
{[52]}\end{array}$ \\
\hline $\begin{array}{l}\operatorname{Atg} 7^{\mathrm{f} / \mathrm{f}} \times \text { CD4-Cre } \\
\operatorname{Atg} 7^{\mathrm{f} / \mathrm{f}} \times \text { Gzmb-Cre }\end{array}$ & $\begin{array}{l}\text { Memory T- } \\
\text { cells }\end{array}$ & $\begin{array}{l}\text { Failed protection against secondary } \\
\text { infection. Mechanism unclear, glycolytic } \\
\text { phenotype and mitochondrial damage }\end{array}$ & $\begin{array}{l}{[45]} \\
{[47]} \\
{[48]}\end{array}$ \\
\hline $\begin{array}{c}\operatorname{Atg} 5^{-/-}->\operatorname{Rag}^{-/-} \\
\text {chimera } \\
\operatorname{Atg} 5 / 7^{\mathrm{f} / \mathrm{f}} \times \mathrm{CD} 19-\mathrm{Cre} \\
\operatorname{Atg} 5^{\mathrm{f} / \mathrm{f}} \times \mathrm{Mb} 1-\mathrm{Cre}\end{array}$ & $\begin{array}{l}\text { Pro-to pre-B } \\
\text { cell (contro- } \\
\text { versial) } \\
\text { B1-a cells }\end{array}$ & Mechanisms unclear & $\begin{array}{l}{[60]} \\
{[43]} \\
{[59]} \\
{[61]}\end{array}$ \\
\hline $\operatorname{Atg} 5 / 7^{\mathrm{fif}} \times \mathrm{CD} 19-\mathrm{Cre}$ & Plasma cells & $\begin{array}{l}\text { Sustained immunoglobulin production, } \\
\text { limiting the unfolded protein response }\end{array}$ & {$[62]$} \\
\hline $\begin{array}{c}\operatorname{Atg} 5 / 7^{\mathrm{f} / \mathrm{f}} \times \mathrm{CD} 19-\mathrm{Cre} \\
\operatorname{Atg} 5^{\mathrm{f} / \mathrm{f}} \times \mathrm{Mb1}-\mathrm{Cre}\end{array}$ & $\begin{array}{l}\text { Memory B- } \\
\text { cells }\end{array}$ & prevention of lipid peroxidation & {$[63]$} \\
\hline 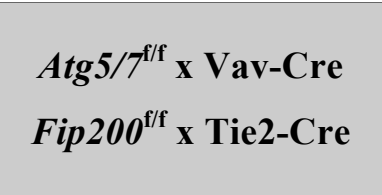 & $\begin{array}{c}\text { Hematopoietic } \\
\text { stem cell }\end{array}$ & $\begin{array}{c}\text { Loss of self-renewal capacity, BM failure, } \\
\text { mitochondrial dysfunction, }\end{array}$ & $\begin{array}{l}{[24]} \\
{[25]} \\
{[26]}\end{array}$ \\
\hline $\begin{array}{c}\text { Bnip3L } L^{-/-} \\
\operatorname{Atg} 7^{\mathrm{f} / \mathrm{f}} \times \text { Vav-Cre } \\
\operatorname{Atg} 7^{\mathrm{f} / \mathrm{f}} \times \text { ErGFP-Cre }\end{array}$ & Erythrocyte & $\begin{array}{c}\text { Anemia, defective } \\
\text { mitochondrial/organelle clearance }\end{array}$ & $\begin{array}{c}{[36]} \\
{[37]} \\
{[38]} \\
{[39][40]} \\
{[41]}\end{array}$ \\
\hline
\end{tabular}




\begin{tabular}{|c|c|c|c|}
\hline $\begin{array}{c}\operatorname{Atg}^{\mathrm{f} / \mathrm{f}} \times \mathrm{NKp} 46-\mathrm{Cre} \\
\operatorname{Atg}^{\mathrm{f} / \mathrm{f}} \times \text { ERT2-Cre } \\
\text { Bnip3L }^{\mathrm{f} / \mathrm{f}} \times \text { NKp46-Cre } \\
\text { Bnip }^{-/-}\end{array}$ & $\begin{array}{c}\text { Innate } \\
\text { lymphoid cells }\end{array}$ & $\begin{array}{l}\text { Loss of NK cells and memory NK cells, } \\
\text { mitochondrial dysfunction, mechanism } \\
\text { unclear }\end{array}$ & $\begin{array}{l}{[73]} \\
{[74]}\end{array}$ \\
\hline $\begin{array}{c}\operatorname{Atg} 7^{\mathrm{f} / \mathrm{f}} \times \text { Vav-Cre } \\
\text { Human PBMCs }\end{array}$ & $\begin{array}{l}\text { Monocyte- } \\
\text { Macrophage }\end{array}$ & Prevention of apoptosis/caspase activation & $\begin{array}{c}{[20][65]} \\
{[66]} \\
{[67]}\end{array}$ \\
\hline
\end{tabular}

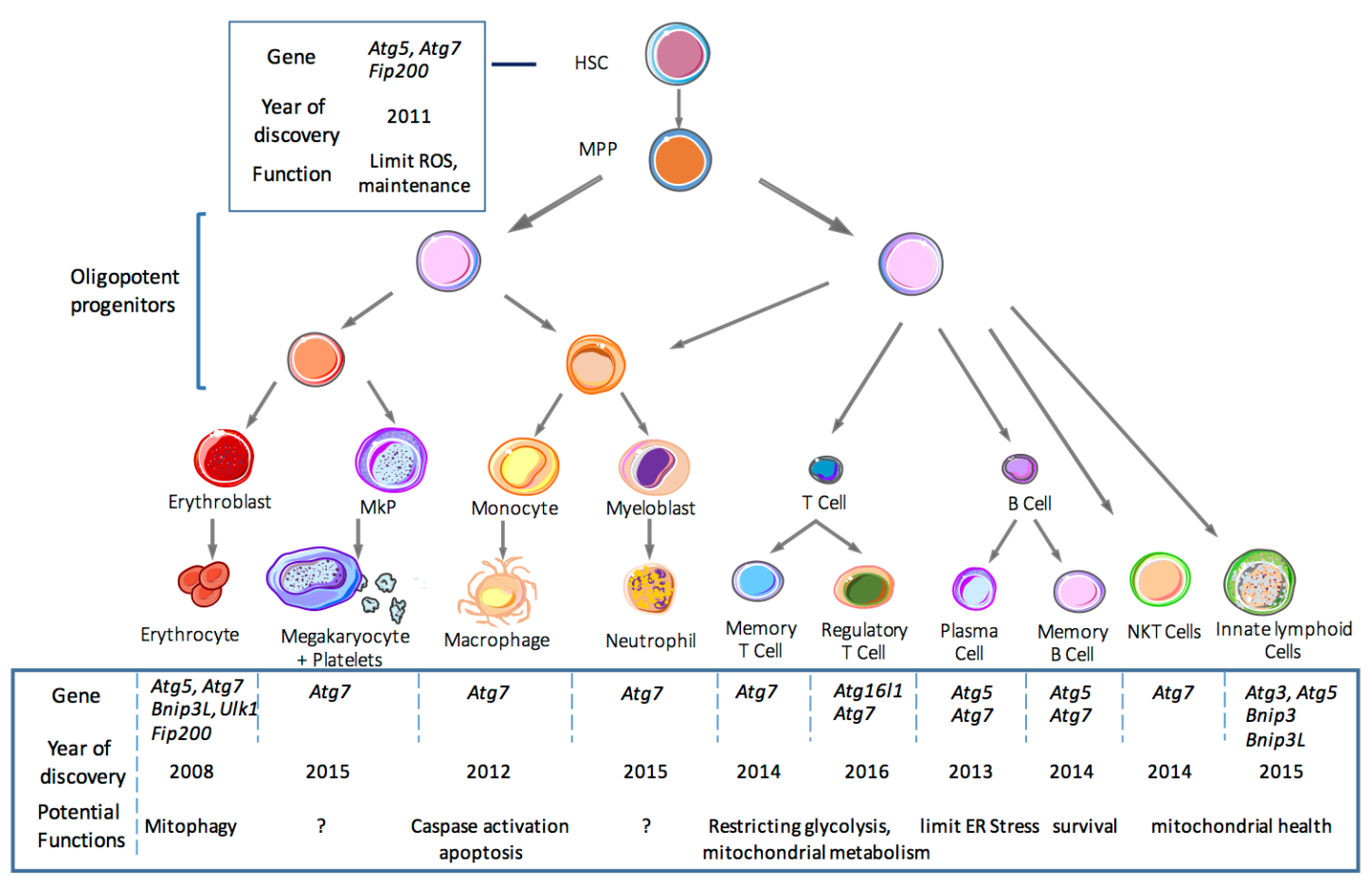

Figure 2 Summary of differentiation steps that involve autophagy

Autophagy plays a crucial role in hematopoietic differentiation at several stages. Summarized here are the specific stages that require autophagy, as well as the autophagy factors that were deleted in each system along with the year of first description and a keyword on the putative mechanistic involvement of autophagy. For details on each cell type, please refer to the relevant section. HSC hematopoietic stem cell; MPP multipotent progenitor; MkP Megakaryocyte progenitor; NKT Natural Killer T Cell; 